\title{
JESUS COMO SIMBOLISTA E ANTIRREALISTA: SOBRE A INTERPRETAÇÃO SEMIÓTICA DE NiETZSCHE N'O ANTICRISTO ${ }^{1}$
}

\author{
André Luis Muniz Garcia $\left(\mathrm{UnB}^{2}\right)^{2}$ \\ andrelmg@hotmail.com
}

Resumo: Esse artigo pretende discutir, em um primeiro momento, o sentido, para a psicologia de Nietzsche, da figura de Jesus n'O Anticristo. Mais precisamente, esse artigo parte de uma problematização dessa tipologia de Jesus, para, em seguida, fazer convergir essa estratégia psicológica com uma semiótica, isto é, uma análise do uso dos signos pelo tipo Jesus. Depois de contextualizar a discussão sobre o tipo Jesus como "simbolista" e "antirrealista", mostramos como Nietzsche, estrategicamente, elabora em suas últimas obras uma efetiva confrontação simbólica entre o tipo Jesus e Dioniso, e a partir disso buscamos indicar algumas conclusões.

Palavras-chave: Nietzsche; signo; Jesus; Dioniso.

\section{Problematização: A tipologia de Jesus}

Uma das interpretações-chave de Nietzsche na obra O Anticristo (doravante, $\mathrm{AC}$ ) é a que visa a uma tipologia de Jesus. Ela tem início em AC 24, que trata do surgimento do cristianismo a partir do espírito do judaísmo, sendo tal perspectiva precedida, por sua vez, por uma importante série de três seções $(21,22$ e 23), nas quais Nietzsche se deteve cui-

\footnotetext{
${ }^{1}$ Recebido: 04-09-2016/ Aceito: 10-11-2016/ Publicado online:19-01-2017.

${ }^{2}$ André Luis Muniz Garcia é Professor Adjunto da Universidade de Brasília, Brasília, DF, Brasil.
} 
dadosamente em uma interpretação do distinto estatuto religioso do budismo (enquanto práxis religiosa niilista) e do cristianismo (enquanto teoria moral-religiosa decadente). Essa distinção descortinou, em AC, um novo campo de investigação, qual seja, de que, porquanto o cristianismo representaria uma teoria para a civilização do tipo "bárbaro", fundada em três "virtudes" cardinais - fé, amor e esperança -, o budismo é uma práxis para a "civilização", para a "domesticação" do próprio sofrimento (AC 22). Isso quer dizer que, escreve o filósofo na seção 23 de AC, se para o cristianismo a pergunta pelo sofrimento coincide com uma interpretação cristã sobre a existência, para o budismo, não há uma pergunta pelo sofrimento, já que ele tem que ser pensando do ponto de vista da natureza do homem. Do ponto de vista da existência, pergunta-se o cristão pelo por que da dor; no caso do budismo, a dor é a própria natureza, ela não é apenas inerente à existência, mas sua essência. Um budista, exemplifica Nietzsche sua posição, jamais sofreria por algo como o pecado ${ }^{3}$ Nesse sentido, o budismo representaria uma peculiar interpretação sobre o estatuto do sofrimento, já que nele não caberia se questionar sobre algo que é dado ${ }^{4}$

\footnotetext{
${ }^{3}$ Cf. AC 23: „Der Buddhismus, nochmals gesagt, ist hundert Mal kälter, wahrhafter, objektiver. Er hat nicht mehr nöthig, sich sein Leiden, seine Schmerzfähigkeit anständig zu machen durch die Interpretation der Sünde, - er sagt bloss, was er denkt, ich leide'. Dem Barbaren dagegen ist Leiden an sich nichts Anständiges: er braucht erst eine Auslegung, um es sich einzugestehn, dass er leidet (sein Instinkt weist ihn eher auf Verleugnung des Leidens, auf stilles Ertragen hin) Hier war das Wort ,Teufel' eine Wohlthat: man hatte einen übermächtigen und furchtbaren Feind, man brauchte sich nicht zu schämen, an einem solchen Feind zu leiden. -, In KSA 6, pp. 180-90. As obras de Nietzsche serão citadas a partir da seguinte tradução. NIETZSCHE, F. Sämtliche Werke: Kritische Studienausgabe in 15 Bänden. Hg. G. Colli und M. Montinari. Berlin/New York: Walter de Gruyter/DTV, 1999. As traduções são de responsabilidade do autor.

${ }^{4}$ Como já mostrou a pesquisa especializada, a interpretação de Nietzsche do budismo é devedora da obra do indologista alemão, Hermann Oldenberg, Buddha: Sein Leben, seine Lehre, seine Gemeinde (1881).
} 
Daí os adjetivos que Nietzsche emprega nessa série de seções supramencionadas, no sentido de salientar que o budismo é uma religião "mais fria, mais verídica, mais objetiva" (AC 23) que o cristianismo, o qual representaria, por seu lado, um sentimento reativo, uma "inimizade mortal (Todfeindschaft)" contra o espírito, contra o orgulho, contra os sentidos, em suma, contra os "nobres" (AC 21); representa a falsificação de valores como o amor, a fé e a esperança. Seguir-se-ia daí sua força para civilizar os "bárbaros” por meio de subjugação dos seus valores. A seção 24, que encena os primeiros passos de sua psicologia do tipo redentor, constitui-se assim como tentativa de entender, criticamente, as razões de uma inimizade mortal à existência, que é, no caso do cristianismo, genética.

Essa psicologia, que caracteriza concomitantemente a problematização da origem do cristianismo, é regulada por duas diretrizes metodológicas: (i) que o cristianismo não foi um contra-movimento ao que Nietzsche denomina "instinto judeu”, mas sim a consumação da lógica de sua casta sacerdotal, ou seja, o trabalho de esvaziamento de sentido de tudo que é natural, tudo que é natureza, do valor de qualquer realidade 5 , e (ii) que o tipo "nazareno" foi falseado,

\footnotetext{
${ }^{5}$ AC 24: „Die Juden sind das merkwürdigste Volk der Weltgeschichte, weil sie, vor die Frage von Sein und Nichtsein gestellt, mit einer vollkommen unheimlichen Bewusstheit das Sein um jeden Preis vorgezogen haben: dieser Preis war die radikale Fälschung aller Natur, aller Natürlichkeit, aller Realität, der ganzen inneren Welt so gut als der äusseren. Sie grenzten sich ab gegen alle Bedingungen, unter denen bisher ein Volk leben konnte, leben durfte, sie schufen aus sich einen Gegensatz-Begriff zu natürlichen Bedingungen, - sie haben, der Reihe nach, die Religion, den Cultus, die Moral, die Geschichte, die Psychologie auf eine unheilbare Weise in den Widerspruch zu deren Natur-Werthen umgedreht". In KSA 5, 191-2. Em AC 27, Nietzsche volta a afirmar: „Auf einem dergestalt falschen Boden, wo jede Natur, jeder Natur-Werth, jede Realität die tiefsten Instinkte der herrschenden Klasse wider sich hatte, wuchs das Christenthum auf, eine Todfeindschafts-Form gegen die Realität, die bisher nicht übertroffen worden ist“. In. KSA 6, p. 197
} 
por economia institucional, pela interpretação evangelista e, em especial, paulina, intepretação que teria então alavancado a compreensão cristã da existência ao status de dominante. Ambas diretrizes propõem abertamente uma audaciosa e polêmica distinção entre Cristo e Judaísmo, entre Cristo e a Doutrina Cristã. Numa divisão geral dessas duas tarefas, pode-se constatar que a série de seções de 24 a 27 de AC trata do primeiro tópico, e a série de seções entre 28 a 35, do segundo. Essa segunda diretriz de investigação, presente nas seções 28 a 35, segue, aliás, um claro movimento genealógico que se propõe refletir sobre casos extremos de patologia, perspectiva que dominou sua filosofia a partir de 1888, inicialmente com O Caso Wagner (representando ali a psicologia do tipo artista), passando, então, pelo Anticristo (psicologia do tipo religioso) e culminando em sua autogenealogia, Ecce homo (enquanto autocrítica do tipo "Nietzsche"). Ater-me-ei ao segundo tópico antes mencionado, por nele encontrar a temática que aqui pretendo apresentar e discutir, qual seja, a de que Jesus representa, para a psicologia nietzscheana, um tipo simbolista e antirrealista.

2. CONTEXTO: Jesus ENQUANTO SIMBOLISTA E ANTIRREALISTA OU DE COMO SIGNIFICAR DE MODO AMBÍGUO A REALIDADE

Chama atenção o fato de que Jesus, no contexto da seção 27 de AC, que trata da revolta cristã contra o judaísmo institucionalmente estabelecido, contra a "igreja judaica”, aparece como ideólogo da revolução, como caudilho do levante das camadas mais populares, como "anarquista sagrado" que pretendia contradizer a ordem social estabelecida, isto 
é, revolver a hierarquia dos valores da sociedade judaica daí o caráter iminentemente político que Nietzsche, seguindo toda uma tradição alemã, do jovem Hegel à esquerda hegeliana, confere a Jesus. Como bem mostrou Andreas Sommer, Nietzsche abre ali franca discussão com teses do teólogo francês Ernest Renan, em seu livro Vie de Jésus $(1864)^{6}$, defendendo a perspectiva segunda a qual Jesus, em sua agitação política, não teria sido preso e morto na cruz senão "pela sua culpa -", e prossegue: "falta fundamento para isto, que frequentemente foi afirmado, a saber, que ele morrera pela culpa dos outros. -" (AC 27). Para Renan, por outro lado, não restaria dúvida de que a posição política de Jesus, bem como as consequências dela, tinham como propósito a mais pura afirmação dos interesses das classes inferiores, visando a redimi-las de toda submissão e a elas conferir, em virtude de sua força e vontade heroicas, um reino sagrado, já que o Cristo fora capaz de enfrentar exemplarmente uma sorte incomum. ${ }^{7}$ Para as pretensões de Nietzsche, no entanto, tal como o fez Renan, uma análise

\footnotetext{
${ }^{6}$ Cf. RENAN, E. Vie de Jésus. Michel Lévy Frères Libaires Editeurs: $2^{a}$ Ed. Paris, 1864. « Ce qui distingue, en effet, Jésus des agitateurs de son temps et de ceux de tous les siècles, c'est son parfait idéalisme. Jésus, à quelques égards, est un anarchiste, car il n'a aucune idée du gouvernement civil. Ce gouvernement lui semble purement et sim- plement un abus. "Aqui, p. 127. Seguiremos, em alguns pontos, o importante comentário histórico-crítico de A. U. Sommer ao Anticristo. Cf. SOMMER, A. U. Friedrich Nietzsches 'Der Antichrist': Ein philosophisch-historischer Kommentar. Basel: Schwabe \& CO. AG Verlag, 2000. A referência ao contexto ora discutido encontra-se na página 269.

${ }^{7}$ "Qui établira ce règne de Dieu? Rappeions-nous que la première pensée de Jésus, pensée tellement profonde chez lui qu'ellç n'eut probablement pas d'origine et tenait aux racines mêmes de son être, fut qu'il était le fils de Dieu, l'intime de son Père, l'exécuteur de ses volontés. La réponse de Jésus à une telle question ne pouvait donc être douteuse. La persuasion qu'il ferait régner Dieu s'empara de son esprit d'une manière absolue. Il s'envisagea comme l'universel réformateur. Le ciel, la terre, la nature tout entière, la folie, la maladie et la mort ne sont que des instruments pour lui. Dans son accès de volonté héroïque , il se croit tout-puissant.» In. RENAN, E. op. cit., pp. 118-9.
} 
histórico-social do redentor, visando a compreender suas intenções políticas, externa certa displicência com o método. Ele afirma claramente logo no início da seção 28: "E aqui toco apenas o problema da psicologia do redentor", método que, adverte Nietzsche, não segue diretrizes sociológicas, herdadas das narrativas históricas e lendas sobre Jesus ${ }^{8}$, como queria Renan em sua obra: daí Nietzsche ver como infundadas, na seção 29, as afirmações do teólogo de acordo com as quais Jesus nada mais seria do que um tipo "herói e gênio" ".

Nietzsche segue, na apresentação de seu projeto de uma psicologia do redentor em AC 29, um critério aparentemente paradoxal, segundo o qual o tipo psicológico Jesus encontrar-se-ia nos Evangelhos "apesar dos Evangelhos"; ou seja, Nietzsche polemiza com o estatuto e uso tradicional das fontes utilizadas pelos eruditos, pela cristologia da Igreja, para tratar do caso Jesus, uma vez que o filósofo não assume justamente a ortodoxia e autoridade das narrativas evangélicas, pois não lhe interessa "a verdade daquilo que

\footnotetext{
${ }^{8}$ Contra isso, ele afirma em AC 28: „Die Geschichten von Heiligen sind die zweideutigste Litteratur, die es überhaupt giebt: auf sie die wissenschaftliche Methode anwenden, wenn sonst keine Ur. kunden vorliegen, scheint mir von vornherein verurtheilt - blosser gelehrter Müssiggang [...] “. In: KSA 6, p. 199.

${ }^{9}$ É curioso salientar que essa perspectiva é sublinhada por um grande admirador da obra Vie de Jésus, Richard Wagner. Como bem apontou A. U. Sommer, „auch Wagner hatte im Anhang zu Religion und Kunst unter dem Titel 'Heldenthum und Christentum' Jesus als Hyperheros glorifiziert [...] "In. SOMMER, A. U. op. cit., p. 283, nota 131. G. Campioni apresenta ainda com mais detalhes essa admiração pela obra e argumentos de Renan sobre Jesus: "Wagner, en particulier, met en parallèle la fameuse Vie de Jésus de Renan ('il [Richard Wagner] est en accord total avec ses conceptions', écrit Cosima dan son Journal), un vrai 'best-seller' de l'époque, avec celle, tout aussi importante, de Strauss : Das Leben Jesu, de 1835. Dans ces deux reconstitutions, Wagner trouve un aliment pour ses analyses du génie et, plus généralement, du rapport entre raison et religion/mythe. "E complementa: «Le plaine concordance de Wagner avec Renan - qui accompagne le musicien dans la conception de la figure 'heroïque' de Parsifal - prend fin après la publication du Marc Aurèle. "In CAMPIONI, Giuliano. Les Lectures Françaises de Nietzsche. Trad. Christel Lavigne-Mouilleron. Paris: PUF, 2001, p. 53 e 57, respectivamente.
} 
ele [Jesus] fez, do que disse, como ele propriamente morreu: mas sim a pergunta, se seu tipo, em geral, é ainda concebível (vorstellbar), se ele é 'conservado [pela tradição] (überliefert)"' (AC 29). Em resumo, em sua psicologia, Nietzsche pretende tão somente saber se o tipo Jesus é ainda possivel; e, se sim, como se daria tal possibilidade no âmbito estritamente psicológico?

Sua primeira e radical intervenção, no contexto da seção 29, é apontar a incongruência entre um tipo herói e aquele de Jesus: enquanto um caso patológico, Jesus representa, havia já afirmado Nietzsche categoricamente na seção 28 de AC, "a oposição a todo combate, a todo sentir-se-emluta", seu tipo é o de um "não-poder-ser-inimigo" tornado instinto. Jesus é um tipo impotente para o heroísmo, segundo AC 28, um heroísmo paradoxalmente pacífico, um que sente a verdadeira vida no amor redimido do conflito, um afeto que nada mais inclui ou exclui, que não quer a nada mais opor resistência: eis o conceito de amor nazareno enquanto "a única, a última possibilidade de vida" (AC 30). Chama atenção o fato de que, de acordo com essa caracterização, a patologia do tipo Jesus se contrasta abertamente com aquela do cristianismo, que é, por sua vez, um tipo de força, de conflito, é, como se pode ler em AC 21, luta contra todo espírito, orgulho e sentidos do tipo nobre. ${ }^{10}$ Sob esse aspecto, o tipo Jesus desponta como uma ameaçadora possibilidade de supressão daquilo que na vida, segundo uma já conhecida posição de Nietzsche, é a "regra" - a von-

\footnotetext{
${ }^{10}$ É nessa linha argumentativa que Nietzsche vai criticar também o conceito de gênio atribuído a Jesus por Renan: „Und was für ein Missverständniss ist gar das Wort ,Genie’! Unser ganzer Begriff, unser Cultur-Begriff ,Geist' hat in der Welt, in der Jesus lebt, gar keinen Sinn." AC 29. In KSA 6, p. 200.
} 
tade de poder: quanta de força que estão em ininterrupto conflito; em outras palavras, começa a se visualizar o extremo perigo - isto que talvez represente uma das mais importante teses d'O Anticristo ${ }^{11}$ - de um tipo que poderia ser concebido para além (ou aquém) da vontade de poder.

Em AC 29, tal tipo vai sendo pouco a pouco caracterizado como

[...] instinto-de-ódio contra toda realidade, como fuga para o 'incompreensível', para o 'inapreensível', como má-vontade ante toda fórmula, todo conceito de tempo e espaço, contra tudo que é fixo, [tudo que é] costume, instituição, igreja, como estar-em-casa em um mundo no qual nenhuma realidade mais afeta [...]. (AC 29)

Já em $\mathrm{AC}$ 30, as duas condições fisiológicas diagnosticadas no tipo Jesus, isto é, as condições para o estabelecimento do que ali chama "doutrina da redenção", são apresentadas com destaque: "O instinto-de-ódio contra a realidade [...]" e o "instinto-de-exclusão de toda inclinação, de toda inimizade, de todos os limites e distâncias no sentimento [...]". O primeiro, caracterizando-se pela extrema (e paradoxal) capacidade excitativa de um "não mais querer ser 'afetado"; o segundo, pela capacidade de perceber qualquer resistência, conflito, oposição como "desprazer insuportável”, como algo "danoso", como algo que representaria uma abdicação "do instinto de conservação". O tipo Jesus não é tomado por Nietzsche simplesmente como decadente, ele é, isto sim, "o mais interessante décadent", um tipo, escreve agora na seção 31 de AC, "cuja aparição sugere [algo] como Buda

\footnotetext{
${ }^{11}$ Consultar a defesa desse argumento em: STEGMAIER, W. "A crítica de Nietzsche da razão de sua vida - Para uma interpretação de O Anticristo e Ecce homo". In. STEGMAIER, W. As linhas fundamentais do pensamento de Nietzsche. São Paulo: Vozes, 2014.
} 
em um solo pouco indiano”. Ambos, Jesus e Buda, são aqui psicologicamente equiparados em virtude de sua práxis (guardadas, claro, as distinções "geográficas" e de estratégia argumentativa): representariam, cada um à sua maneira, a constante possibilidade fisiológica de anulação contínua tanto do próprio sentimento de poder (que caracteriza o tipo "bom" [AC 2]) quanto do sentimento que deriva da impotência dos instintos (o tipo "ruim"). ${ }^{12}$ Sob esse aspecto, e tomando de empréstimo uma expressão conhecida empregada por Nietzsche em O Caso Wagner, seção 7, o tipo redentor poderia ser tomado como a ocorrência mais interessante da "desagregação da vontade", enquanto uma

\footnotetext{
${ }^{12}$ Como sugere o comentário clássico de W. Müller-Lauter: "Whoever, like the Jesus whom Nietzsche has in mind, dissolves in his interiority the opposites that are supposed to be the truly real, can as denier of reality still be merely decant. Christianity, then, in its very origins is 'a form of mortal hostility to reality as yet unsurpassed" (AC 27). Now Jesus' decadence, this most extreme denial of reality, opposes the decadence-instincts supported by Judaism. [...] And it has nothing in common with the continuation of the decadence-movement that refers to his name. [...] In Nietzsche's view, Jesus' activity thus appears as a break in the history of decadence. Can Jesus, then, be a decant at all? Evidently only if he represents a decadence that remains foreign to the movement of decline that reject him. What speaks for a such view on Nietzsche's part is that traces of Buddhism are detectable in his image of Jesus. For, according to Nietzsche, in Buddhism, decadence has been carried to a point not uet reached in the history of Christianity. [...] Jesus, too, stands beyond all morality. And like him the Buddhist rejects the "struggle against those who think differently" and resists "nothing more than it resists the feeling of revengefulness, of antipathy, of ressentiment" (AC 20, cf. Will to Power 159). [...] On the other hand, Nietzsche does not want to blur the difference between Jesus and Buddha. He makes them clear by pointing out the particular conditions under which Buddhism originated. It is rooted in a centuries-old philosophical tradition. [...] As a 'non-Indian Buddha', Jesus towers over his time. And as Buddhism 'later' than Christianity, Jesus, too, has bypassed its entire history until now. His unfalsified doctrine would first find its historical place in a European Buddhism, whose gradual rise Nietzsche believes to perceive in his own time. [...] Nietzsche can come only to a conclusion: this practice must be constant possibility of man." MÜLLER-LAUTER, W. His Philosophy of Contradictions and the Contradictions of his Philosophy. Translated by David J. Parent. Urbana and Chicago: University of Illinois Press, 1999, pp. 53-4. Na mesma direção, A. U. Sommer: „Freilich konterkariert in der antichristlichen Geschichtskonstruktion nicht die Praxis Jesu die Leidensbewältigung Buddhas. Beiden stellt Nietzsche im Gegenteil ein kirchliches, das heisst für ihn: paulinisches Christentum entgegen, das seine Welt- und Leidenserfahrung bereits in moralische, metaphysische und theologische Begriffe transsubstantiiert - ja überhaupt erst Begriffe gefunden hat, die in der Distanzlosigkeit Jesu noch undenkbar waren." In. SOMMER, A. U. op. cit. p. 208
} 
tendência de dissolução fisiológica dos quanta de força em um organismo.

Desse contexto se segue a sempre criticada por Nietzsche aproximação entre Jesus e Cristianismo, já que, por consequência do exame psicológico, o tipo Jesus não poderia ter sua origem no espírito do judaísmo, ou dito de outra maneira: sua essencial prática da não-oposição, da nãoresistência, sua dissolução de todo conflito e inimizade em um sentimento extremo de "não querer mais ser afetado", não pode ser psicologicamente derivada da matriz judaica, o que implica dizer que o tipo Jesus não pode ser pensado como elemento mediador entre judaísmo e cristianismo como se sabe, para cumprir esse papel Nietzsche sugere a figura de Paulo. Em AC, aliás, Nietzsche exemplifica sua hipótese tomando uma das três virtudes teologais vitais do cristianismo, a fé, com o intuito de mostrar mais uma vez a imprecisão da interpretação teológica (ele tem em mente Renan) do tipo redentor. A infantil idiotia (no sentido dostoievskiano) de Jesus (AC 31) corrobora uma peculiar concepção de fé, que nada traz consigo de combativo: "Uma tal fé", prossegue Nietzsche agora em AC 32, "não se enraivece, não censura, não se volta contra nada: não traz 'a espada ${ }^{13}[. .$.$] Ela não é demonstrada nem por milagres, nem por$ recompensa ou promessa, nem mesmo 'pela Escritura' [...]. Essa fé também não se expressa por fórmula - ela vive, ela volta-se contra as fórmulas". Em suma: a fé do Cristo não pode por nenhuma razão (que não a institucional) ser pensada como uma doutrina, no sentido de um conjunto siste-

\footnotetext{
${ }^{13}$ A contraposição aqui é à interpretação judaica de Mateus do Cristo: "Não suponhais que vim trazer paz à terra; não vim trazer paz, mas espada;" Mateus 10:34.
} 
mático de conceitos e regras passíveis de integral transmissão ou comunicação, uma vez que não há nela nenhuma "fórmula", não há nela nenhum "preceito" ou "princípio", ou melhor, nada tem seu sentido e significado estabilizado, inequívoco, justamente porque nela a escrita não tem qualquer valor, a linguagem escrita não é para essa fé o "corpo" das verdades que carrega. Pelo contrário, assevera Nietzsche em AC 32, a linguagem da qual essa "infantilizante" fé se vale é aquela da plena ambiguidade, ela é um fenômeno genuíno da mais extrema polissemia, da indiferença no uso dos signos, da significação ingenuamente alegórica das realidades interna e externa. É desse contexto que emerge sua interpretação, a nós cara, do tipo de linguagem da fé cristã:

Todavia, guarde-se de ver nisso mais do que discurso de signos, semiótica, uma oportunidade para alegorias. Justamente porque nenhuma palavra é tomada ao pé da letra, eis a pré-condição para esse antirrealista poder falar. (AC 32)

Esse trecho marca uma original interpretação de Nietzsche sobre a comunicação da fé, sobre a transmissão da "boa nova" do Cristo. Em seu "indiferente" uso dos signos, Jesus nada designa, apenas alude, apenas "deixa entrever", jamais fixa ou denota algo com palavras ou conceitos, mas "polissemiza”, torna tudo que vê, sente, toca, de sentido ambíguo. Com a expressão "não tomar nenhuma palavra ao pé da letra”, Nietzsche pretende esclarecer o modus operandi dessa alusão polissêmica do real. Os signos dos quais se vale o Cristo para exprimir algo são signos que não adquirem significação determinada, não portam um interesse específico de apropriação, característica fundamental do interpretar enquanto vontade de poder; são signos dos quais jamais 
se pode ter uma compreensão ou interpretação suficientes. Ora, signos pelos quais não perguntamos mais sobre seus significados são signos "tomados ao pé da letra", ou seja, são signos que foram suficientemente entendidos. Signos "tomados ao pé da letra" são signos tornados, de alguma maneira, inteligíveis, tornados compreensíveis por um outro indivíduo ou por um grupo. Em seu uso regular, signos "tomados ao pé da letra" alçam-se àquilo que Nietzsche chama de "fórmulas", já que, por não pairarem sobre eles qualquer questionamento quanto à significação, isso implica dizer que eles estabilizam e fixam sentidos, pois tais critérios servem como preceitos para uma comunicação convencional. É nesse sentido que Nietzsche adverte, novamente em AC 31:

[...] ele não se importa com nada que é fixo: a palavra mata, tudo que é fixo mata. O conceito, a experiência "vida", tal como somente ele a conhece, se opõe, nele, a todo tipo de palavra, fórmula, lei, crença, dogma. Ele fala apenas da interioridade: "vida" ou "verdade" ou "luz" é sua palavra para a interioridade, - todo o resto, toda a realidade, toda a natureza, mesmo a linguagem, têm para ele simplesmente o valor de um signo, de uma alegoria. (AC 32)

Jesus nada quer tornar fixo com seus signos, exatamente porque nada quer apreender, sua intenção é apenas aludir. Isso ele o faz por meio de transmissão de signos que não podem ser apreendidos senão muito ambiguamente, e justo aqui ter-se-ia um modo especial de interpretação, a saber, aquela que não fornece sequer um sentido determinado em seu entendimento de algo. Sua interpretação não se constitui como um querer empoderar-se de algo, pois seus sentidos, valores, seus signos denotam apenas sua indiferença com a exterioridade. A possiblidade de tornar algo em "algo inte- 
ligível" para outro indivíduo ou para um grupo, por meio de palavra, fórmula, lei, crença ou dogma, não encontra correspondência na semiótica do Cristo, uma linguagem que, a dizer de modo preciso, não doutrina. ${ }^{14} \mathrm{O}$ uso indiferente de signos para dar sentido à realidade, enquanto resultado de seu extremo não-querer-mais-dar uma interpretação determinada, não querer dar-seu-sentido para algo, constitui o traço essencial do valor simbólico de Jesus na psicologia nietzscheana. É ele mesmo, o tipo Jesus, uma simbólica para o tornar-obscuro semioticamente toda realidade; ou a dizer como o próprio Nietzsche, ele mesmo uma "fuga para o "incompreensível', para o 'inapreensível”' (AC 29).

Uma tal simbólica par excellence encontra-se fora de toda religião, de todos os conceitos de culto, de toda história, de toda ciência natural, de toda experiência de mundo, de todo conhecimento, de toda política, de toda psicologia, de todos os livros, de toda arte - seu "saber" é apenas a pura idiotice de que algo desse tipo exista. (AC 32)

\section{Psicologia do Simbolista ENQUANTO SEMIÓTICA: JESUS COMO SIGNO}

Nietzsche persegue insistentemente uma caracterização psicológica mais profunda dessa simbologia do Cristo, que aqui nos interessa sobremaneira: uma psicologia do tipo redentor deve, por razões metodológicas, convergir com uma intepretação semiótica desse que é, a dizer como Nietzsche em AC 34, o "grande simbolista". Não parece, entretanto, mero diletantismo que o leitor recupere em sua lembrança

\footnotetext{
${ }^{14}$ „Eine solche Lehre kann auch nicht widersprechen, sie begreift gar nicht, dass es andre Lehren giebt, gebenkann, sie weiss sich ein gegentheiliges Urtheilen gar nicht vorzustellen [...] " AC 33. KSA 6, p. 204.
} 
involuntariamente um contexto aparentemente exterior ao da obra, quando se depara com tais predicados atribuídos ao tipo Jesus, quais sejam, simbolista e antirrealista. Do ponto de vista da história da poesia, da literatura e da pintura, em especial como se pode observar na primeira metade do século XIX, simbolista e antirrealista são designações equivalentes, não apenas porque o simbolismo é tratado como um contramovimento ao realismo e ao naturalismo, mas, antes de mais nada, porque para o simbolista a palavra ou o signo imagético - em suma: o símbolo - não é mais empregado em um sentido comum (tradicional), mas, como adverte Anna Balakian, é tomado "em associação com aquilo que ela [a palavra] evoca de uma realidade situada além dos sentidos". 15 Nietzsche não só conhecia, com precisão, os termos que empregava em sua caracterização do tipo redentor, como também havia proposto empreender um estudo mais profundo de uma das principais fontes desse movimento, a saber: a poesia lírica de Charles Baudelaire ${ }^{16}$, poeta francês, confesso admirador da linguagem operística de Richard Wagner. Quanto a Baudelaire, Nietzsche tomou

\footnotetext{
${ }^{15}$ Cf. BALAKIAN, Anna. O Simbolismo. Trad. José Bonifácio A. Caldas. São Paulo: Editora Perspectiva, 1985, aqui p. 12.

${ }^{16}$ Sobre o tema, consultar: PESTALOZZI, K. „Nietzsches Baudelaire-Rezeption“ In: NietzscheStudien 7, 1978. Ele comenta sobre o interesse de Nietzsche em sua recepção de Baudelaire: „Für die Datierung dieser Lektüre der Fleurs du Mal gibt es nur indirekte Anhaltspunkte. In den Notizheften ,1. April-Juni 1885' und ,Juni-Juli 1885' finden sich Erwähnungen Baudelaires, die sich als Reflexe dieser Lektüre betrachten lassen. Sie bringen Baudelaire mit Wagner in Verbindung und bestätigen damit Nietzsches rückblickende Äußerung gegenüber Gast, er habe in den Fleurs $d u$ Mal, eine Art Wagnerische Sensibilität' gefunden. [...] Die Anregung, Baudelaire zu lesen, dürfte von Paul Bourget ausgegangen sein, dessen 1. Band der Essais de psychologie contemporaine, in denen sich der große Baudelaire-Aufsatz befindet, Nietzsche im März [1888] mit großer Zustimmung gelesen hat. [...] Der ,Erwartungshorizont', rezeptionstheoretisch gesprochen, mit dem Nietzsche bei der ersten Lektüre an Baudelaire herantrat, war beherrscht von Richard Wagner“. Aqui, pp. 160-1.
} 
conhecimento de sua poesia, provavelmente, a partir da leitura, na primeira metade dos anos de 1880, de uma das obras que mais influenciou sua madura psicologia e sua teoria da decadência ${ }^{17}$ : a saber, a obra de Paul Bourget, Essais de Psychologie Contemporaine, obra que, por se tratar de uma compilação de artigos, foi publicada integralmente somente em 1889.

Seguindo de perto a interpretação de Bourget sobre Baudelaire, Nietzsche julgava também visualizar no poeta francês as coordenadas para a compreensão do ideal moderno do fin de siècle, que alimentou importantes correntes artísticas e filosóficas oitocentistas, das quais podemos destacar duas: na arte, Richard Wagner, e, na filosofia, Arthur Schopenhauer. ${ }^{18}$ Pessimismo, niilismo, mal du siècle, são características pontuadas por Bourget, logo no primeiro capítulo de sua obra, em uma análise da "teoria da decadência" de Baudelaire. ${ }^{19}$ A partir desse contexto, interessava a Bourget

\footnotetext{
${ }^{17}$ Justamente no terceiro tópico, presente no capítulo dedicado a Baudelaire, denominado "Théorie de la décadence», Nietzsche extraiu a espinha dorsal de suas considerações sobre o conceito décadence. Bourget afirma: "[Baudelaire] s'est rendu compte qu'il arrivait tard dans une civilisation veillissante, et, au lieu de déplorer cette arrivée tardive, comme La Bruyère et comme Musset, il s'en est réjoui, j'allais dire honoré. It était un homme de décadence, et il s'est fait un théoricien de décadence. [...] Par le mot décadence, on désigne volontiers l'état d'une société qui produit un trop petit nombre d'individus propres aux travaux de la vie commune. Une société doit être assimilée à un organisme. Comme un organisme, en effet, elle se résout en une fédération de cellules. L'individu est la cellule sociale. Pour que l'organisme total fonctionne avec énergie, il est nécessaire que les organisme moindres fonctionnent avec énergie, mais avec une énergie subordonnée, et, pour que ces organismes moindres fonctionnent eux-mêmes avec énergie, il es t nécessaire que leurs cellules composantes fonctionnent avec énergie, mais avec une énergie subordonné. Si l'énergie des cellules devient indépendante, les organismes qui composent l'organisme total cessent pareillement de subordonner leur énergie à l'énergie totale, et l'anarchie qui s'établit constitue la décadence de l'ensemble. L'organisme social n'échappe pas à cette loi ». BOURGET, Paul. Essais de Psychologie Contemporaine. Édition établie et préface par André Guyaux. Paris: Gallimard, 1993, pp. 13-14.

${ }^{18}$ É o próprio Nietzsche que os destaca em um longo apontamento póstumo de junho - julho de 1885, in KSA 11, 38 [5], pp. 598-601.

${ }^{19}$ Nessa direção, comenta André Guyaux em seu prefácio à obra de Bourget. « Le vieux mal qu'il Cont.
} 
analisar um decisivo traço do século XIX, a saber, aquele determinado por um romantismo tardio, profundamente marcado pelo pessimismo ante qualquer possibilidade de evolução da cultura europeia. Segundo o autor dos Ensaios:

[Baudelaire] pode ser tomado como um exemplar acabado do pessimismo parisiense [...] O pessimismo foi por ele tratado de modo fatal, luminoso raio satânico, diriam os cristãos: "horror do ser, e o gosto, o furioso apetite, pelo nada". (BOURGET, P. op.cit, p. 10)

Neste artigo, não é nossa pretensão explorar essa relação entre Baudelaire, Bourget e Nietzsche, muito menos pontuar a posição de Baudelaire no movimento simbolista; antes, interessa-nos marcar alguns aspectos gerais e estritamente indicativos do papel do símbolo no contexto dessa corrente que pretendeu afrontar o otimismo presente no ideário progressista do século XIX, e, para tanto, iremos nos valer deste (pode-se dizer arbitrário) fio condutor, qual seja: o pessimismo tornado simbolo nesse que é um dos mais expressivos poetas líricos da modernidade.

Partindo da reformulação romântica da concepção de poeta, Baudelaire, em As Flores do Mal, assume, já no primeiro tableau de poemas (Spleen et Idéal), que apenas ele, o poeta, é capaz de perceber as "correspondências" ${ }^{20}$, ou seja,

\footnotetext{
renvoie comme Baudelaire au 'principe inguérissable de péché, de douleur' (p. 248), est réactualisé dans 'le pressentiment de l'inutilité finale de l'effort moderne' (p. 356). C'est cette définition qu'il semble se fixer, à une conception expérimentale du pessimisme comme d'un optmisme déçu : désillusion de l'amour, vanité du progrès, inutilité de l'effort. Doctrine 'désespérante', écrit-il dans une chronique du Parlament, 'qui proclame l'inanité finale des efforts tentés depuis des siècles pour l'amélioration de la vieille humanité'."

${ }^{20}$ Baudelaire destinou um soneto a esse importante conceito, nele, aliás, apresenta claramente seu projeto simbólico. "Correspondences" é um conceito presente não só no pensamento dos simbolistas, mas no pensamento e arte daqueles que flertavam com a doutrina do místico e espiritualista sueco Emmanuel Swedenborg. Consultar em: BAUDELAIRE, C. Les fleures du mal. Préface et commentaire Robert Sctrick. Paris. Édition Pocket: 1998, pág. 33. Sctrick comenta que o soneto Cont.
} 
os laços entre o mundo espiritual e material, e por essa razão deve ser, comenta Anna Balakian, "o mais afastado do mundo, o mais desajeitado no desempenho de atividades puramente humanas" (BALAKIAN, A. op. cit., p. 22). No poema O Albatroz, Baudelaire canta as dores do poeta em um mundo sem espiritualidade, valendo-se de uma rica simbólica: poetas são "grandes aves do mar / que seguem, indolentes, acompanhando a viagem / o navio glissando sobre amaros abismos". Quando preso às tábuas do convés, ou seja, preso à terra, à realidade empírica, o poeta se vê perdido. "O poeta é semelhante ao príncipe das nuvens / que assombra a tempestade e ri do arqueiro; / exilado sobre a terra, em meio a escárnios, / suas asas gigantes o impedem de ir" (BAUDELAIRE, C. op. cit., p. 32). Para Baudelaire, o "movimento" do poeta deve ser semelhante ao da ave: ascender, e o meio para conquistar essa ascensão da realidade é "um esforço constante para conseguir a purificação moral e a apreciação das belezas da terra, que recordam sem cessar que são apenas os símbolos do oculto" (BALAKIAN, A. op. cit., p. 22). O mundo espiritual estaria assim próximo de uma ainda oculta "realidade universal" devido justamente à sua menor dependência dos estímulos exteriores - daqui a função singular da simbólica onírica na poesia de Baudelaire. Enquanto "palavra" ou "imagem" dos sonhos, jamais enquanto abstracta, o símbolo possui ainda conteú-

Correspondences, «sorte de synthèse entre les différentes sensations, est un témoignage de la perceptions suraiguë de Baudelaire, et une introduction à son monde poétique. L'expérience personnelle, secrète et indicible, se dépasse dans la métaphore (le rôle du comme est ici très important), transposition dans un autre registre de l'impression de départ. On appelle parfois synesthésie l'intime contamination de ces registres pour lesquels la langue poétique, non sans une certaine mystique, essaie de restaurer une unité profonde. » In. BAUDELAIRE, C. op. cit, p. 316. 
dos sensíveis. Mas, como sublinhado, seria no tocante à sua característica mística (uma superafetada interioridade sensória) e ao propósito de seus usos que eles divergem de toda tradição romântica. Esses traços são fundamentais para compreender o papel da ascensão (estética) para além do real proposta por Baudelaire, e que terá grande influência no movimento simbolista como tal.

Fora o afastamento tanto quanto possível da realidade sensível exterior, das afecções do mundo, que possibilitara ao simbolismo, via Baudelaire, acessar as formas mais puras do estado poético. Aliás, por meio dessas formas puras não se alcança mais nenhuma sensação de inteligibilidade, porque em sua simbólica própria o poema sequer pode oferecer uma perspectiva de compreensão determinada: a mensagem do poema permanece sempre sucinta e ambígua (BALAKIAN, A. op. cit., p. 42). Baudelaire, como aponta Balakian, via no conceito de "correspondência" uma fonte ímpar do repertório simbólico, repertório de analogias e metáforas que uniria o humano ao divino - e que seria inigualável, justamente, no caso exemplar da Bíblia (BALAKIAN, A. op. cit. p. 30): simbolo é, sob esse aspecto, a alegoria da criação poética na decifração do divino. Símbolo é meio de expressão direta não do divino por meio de palavras e imagens humanas, mas da contraface humana envolvida pelo divino. Símbolo, por fim, possui a energia de tradução de uma espiritualidade universal, porquanto permite uma reavaliação do mundo sensível a partir de alegorias "sobrehumananemente" inspiradas. ${ }^{21}$

\footnotetext{
21 "Em Bénédiction, [Baudelaire] descreve a desorientação do poeta na terra. Encontra o sabor de ambrosia e néctar em tudo que ouve e bebe; conversa com o vento e o céu; e suporta a zombaria Cont.
} 
Ora, não seria mera coincidência enxergar justo aí o simbolismo do tipo Jesus, tal como Nietzsche o concebe, pois é esse contexto que o filósofo parece ter em mente em AC. Todavia, vale ainda dizer com respeito a essa temática, Nietzsche recorrera a essa analogia não só para buscar entender "o caso" Jesus: devido a um certo interesse temático, como mostram projetos de estudo jamais executados e missivas de Nietzsche com amigos, seria mister destacar ainda que para ilustrar como a realidade produz a mais íntima correspondência com a interioridade do poeta, isto é, para exemplificar como o poeta deve incorporar a realidade espiritual enquanto pura interioridade que articula os simbolos como sons musicais, Baudelaire enalteceu, de modo efusivo, diga-se de passagem, a linguagem operística de Richard Wagner. Em seu famoso texto Richard Wagner et "Tannhäuser" à Paris, deixa claro quais efeitos simbólicos essa música e poesia eram capazes de produzir. ${ }^{22} \mathrm{~A}$ música de Wagner oferecera

do público, porque sabe que o propósito de seu ser transcenderá o desdém de seus semelhantes". In. BALAKIAN, A. op. cit., p. 33.

22 "Aucun musicien n'excelle, comme Wagner, à peindre l'espace et la profondeur, matériels et spirituels. C'est une remarque que plusieurs esprits, et des meilleurs, n'ont pu s'empêcher de faire en plusieurs occasions. Il possède l'art de traduire, par des gradations subtiles, tout ce qu'il y a d'excessif, d'immense, d'ambitieux, dans l'homme spirituel et naturel. Il semble parfois, en écoutant cette musique ardente et despotique, qu'on retrouve, peintes sur le fond des ténèbres, déchiré par rêverie, les vertigineuses conceptions de l'opium. À partir de ce moment, c'est-à-dire du premier concert, je fus possédé du désir d'entrer plus avant dans l'intelligence de ces œuvres singulières. J'avais subi (du moins cela m'apparaissait ainsi) une opération spirituelle, une révélation ». In BAUDELAIRE, C. Richard Wagner et «Tannhäuser» à Paris. In. BAUDELAIRE, C. op. cit., p. 237. Nietzsche se mostrou bastante entusiasmado em explorar essa relação entre Baudelaire e Wagner, como expressa numa famosa carta a Peter Gast, de 26 fevereiro de 1888. Ele conta ter comprado as Oevreus posthumes do poeta e nela encontrar uma carta efusiva de Baudelaire a Wagner, que, por certo atraso no recebimento, só veio a responder depois da morte do escritor de As Flores do Mal. Num trecho importante da missiva, ele comenta: „Man hat, in der letzten Zeit seines Lebens noch, wo er halb irre war und langsam zu Grunde gieng, Wagnersche Musik wie Medizin an ihm angewandt". In. NIETZSCHE, F. Sämtliche Briefe. Kritische Studienausgabe. hg. G. Colli u. M. Montinari. Berlin/New York: DTV \& Walter de Gruyter, 1986. Aqui, volume 8, p. 262. Um importante apontamento póstumo sobre o tema, cf. KSA 13, 23 [2] , p. 600. 
ao poeta francês uma espécie de pura ascensão da realidade, oferecera a introvisão de uma realidade mítica plena (despotencializada de elementos religiosos-institucionais), que seria, por sua vez, não uma tradução simbólica daquele almejado estado espiritual, mas puro trabalho livre de criação da "vida interior" - temática que mereceria uma análise à parte.

Do ponto de vista do contexto ora discutido, Baudelaire torna-se a força motriz de um movimento artístico para o qual a energia alegórica do símbolo estaria - e aqui nos aproximaríamos definitivamente da concepção nietzscheana que apresenta o tipo Jesus como simbolista - na força evocativa das palavras, na habilidade de conferir às próprias palavras o poder de imagens. Toda palavra, todo signo sonoro articulado, tem sua potência exatamente na medida em que nenhum sentido fixa, na medida em que não estabiliza significado; assim empregado, o signo é essencialmente fluido e ambíguo, polissêmico, algo que confere sentido apenas de modo alegórico. A linguagem, ela mesma, se torna puro enigma, torna-se metaforicamente paradoxal.

Ora, o que pretende, pergunta-se Nietzsche em AC 34, o tipo Jesus com simbólicas tão repletas de ambiguidade, tais como: "filho de Deus"; "reino de Deus"; "reino dos céus"; "pai" etc.? Não seriam, como sugere Nietzsche, meros símbolos polissêmicos, que tornam ambígua qualquer noção espaço-temporal? Não adviria daí seu antirrelismo, seu não querer significar e se empoderar desta realidade sensivel? E mais: no tipo Jesus, a linguagem não seria tornada enigma para toda e qualquer tentativa de compreensão? Como compreender os signos empregados por aquele que é indiferente no significar? Confessamos que uma resposta preci- 
sa careceria de uma melhor apreciação temática, mas isso não nos desautoriza dizer que Nietzsche procurou interpretar, com grande esforço, isso que na linguagem de Jesus não se deixa facilmente interpretar, determinar: seus símbolos, e é justamente aqui que sua psicologia converge com uma semiótica.

$\mathrm{O}$ tipo Jesus apenas alude à realidade, à natureza, à história, ao espaço e ao tempo (AC 34) por meio de signos que não se deixam apreender facilmente. A tarefa da linguagem do redentor, afirma Nietzsche em uma apontamento preparatório à seção 32 de $\mathrm{AC}$, "é apenas o esclarecer, o prosseguir, o sutilizar, o transfigurar o antigo [...] o abreviar". ${ }^{23}$ "Vontade de abreviar" constitui-se como condição para traduzir alegoricamente em breves e simples signos um já impotente contingente de outros signos, a saber, os signos da interioridade do nazareno. ${ }^{24}$ Mas a isso se contrapõe a própria "vontade de interpretação" de Nietzsche, uma busca por compreender e interpretar mais profundamente aquilo que não se quer deixar interpretar tão facilmente. Essa vontade é manifesta, por exemplo, logo na primeira linha da seção 34 de AC: "Se eu entendo algo desse grande simbolista[...]" Ora, se tomarmos sua psicologia enquanto tipologia de uma forma de vida que produz uma linguagem, que empre-

\footnotetext{
${ }^{23}$ KSA 13, 11 [369] , p. 166. Deve-se dizer que essa interpretação de Nietzsche encontra, surpreendemente, ecos na posição do próprio Renan sobre Jesus. O teólogo afirma, e Nietzsche parece ter certa dívida com tal perspectiva: "L'Église a eu ses époques et ses phases; elle s'est renfermée dans des symboles qui n'ont eu ou qui n'auront qu'un temps : Jésus a fondé la religion absolue, n'excluant rien, ne déterminant rien, si ce n'est le sentiment. Ses symboles ne sont pas des dogmes arrêtés, mais des images susceptibles d'interprétations indéfinies. » In. RENAN, E. op. cit., p. 446.

${ }^{24}$ Cf. AC 34: „Wenn ich irgend Etwas von diesem grossen Symbolisten verstehe, so ist es das, dass er nur innere Realitäten als Realitäten, als ,Wahrheiten' nahm, - dass er den Rest, alles Natürliche, Zeitliche, Räumliche, Historische nur als Zeichen, als Gelegenheit zu Gleichnissen verstand.“ KSA 6, p. 206.
} 
ga signos que não se deixam interpretar tão facilmente, poderíamos deduzir disso que sua tipificação convergiria com uma semiótica, no sentido de que, no fundo, o tipo Jesus é, para o filosofar maduro de Nietzsche, também um signo para um contingente de signos que não se deixam apreender tão facilmente, que não se deixam significar de modo determinado, que sequer pretendem receber uma interpretação. ${ }^{25}$ Contra a "má-vontade" de interpretação da exterioridade pelo nazareno, Nietzsche apresenta em AC, claramente, sua vontade de tipificá-lo enquanto um "caso" para o ambíguo e indiferente uso de signos, para uma indiferente intepretação da realidade, e isso torna o próprio Cristo um signo - se por signo entendermos aquilo que pode ser compreendido. Enquanto signo para signos que não se deixam apreender tão facilmente, o próprio tipo Jesus é tornado positivamente, para o pensamento semiótico de Nietzsche, uma simbólica, contra a qual, diga-se de passagem, o filósofo empreendeu todo seu esforço, neste que viria a ser seu último ano de produção intelectual (1888), com vistas a combatê-la, isto é, com o intuito de trazer tal simbólica cristã para o jogo de forças, no sentido de contra ela empreender sua derradeira "declaração de guerra”, sua "maldição", enxergando justamente nis-

\footnotetext{
${ }^{25}$ Aliás, deve ser dito com certa justiça que Nietzsche leu minuciosamente uma das importantes orientações que Paul Bourget oferece ao psicólogo em seu livro. Sobre ele afirma no capítulo destinada a interpretação justamente do téologo Ernest Renan. Sobre sua metodologia psicológica, Bourget, no capítulo dedicado à análise do escritor e teólogo Ernest Renan, salienta : "C'est le rôle du psychologue de discener ce qu'il y a de force positive et créatrice dans l'une et dans l'autre [subent. na religião e na sociedade], et de diriger, s'il est possible, cette force. La force positive qui se manifeste par les symboles les plus imparfaits est un sens du divin qui'il faut discerner et qui n'est jamais négligeable, car il constitue ce qu'il y a de plus haut dans le cour de l'homme. Comprendre cette part de vérité sans cesser de discerner la part d'illusion, c'est appliquer les procédés hégéliens de la logique des contradictoires [...] Le sage est celui qui voit à la fois que tout est image, préjugé, symbole, et que l'image, le préjugé, le symbole, sont nécessaires, utiles et vrais "In. BOURGET, P. op. cit., pág. 51
} 
so, como narrara em Ecce homo, seu "destino". A psicologia do tipo Jesus, do "grande simbolista", abriria ainda para Nietzsche, nesses poucos dias que lhe restavam antes do colapso mental, um rico e híbrido campo de investigação: qual seja, a semiótica do crucificado.

\section{UMA SIMBÓlICA ANTICRISTÃ: DIONISO COMO CONTRA- SIGNO AO SIGNO JESUS}

Um dos tópicos que mais aproxima $\mathrm{O}$ Anticristo de sua autogenealogia crítica ${ }^{26}$, Ecce homo (doravante, EH), é seguramente o valor de sua semiótica do "Cristo na cruz". Dentre vários motivos, podemos destacar um em especial, a saber, seu contra-símbolo à simbólica cristã para a vida: Dioniso. Ao autoencenar-se a si mesmo como um tipo em $\mathrm{EH}^{27}$, Nietzsche simultaneamente reconhece enquanto uma das "razões de sua vida" a guerra espiritual contra o Cristo. EH (auto)encena, nessa direção, sua mais estratégica e, a nosso ver, vigorosa frente de combate ao signo Jesus, um deus que não mais quer ser afetado, que não mais quer o conflito, não mais quer apresentar sua posição (interpretação, avaliação, sentido), um deus para o qual o sentimento de poder já não mais faz sentido, um deus morto na cruz que não mais quer empoderar-se desta realidade. Em EH, Nietzsche ensaia, concomitantemente, sua mais genuína simbólica de um deus afirmador, para o qual o sentimento de poder re-

\footnotetext{
${ }^{26}$ Sobre EH, enquanto autogenealogia ou "crítica da razão de sua vida", consultar o já citado artigo: STEGMAIER, W. "A crítica de Nietzsche da razão de sua vida - Para uma intepretação de O Anticristo e Ecce homo".

${ }^{27}$ Sobre o tema, consultar: VIESENTEINER, Jorge L. "Estrutura formal e semântica do argumento autogenealógico". In. Cadernos de Filosofia Alemã, v. 20, p. 105-119, 2015.
} 
flete a abundância e o excesso da vida: com seu signo-deus Dioniso, Nietzsche elabora sua mais enérgica polêmica contra a possiblidade de supressão da vontade de poder pelo tipo redentor.

Como a pesquisa recente tem mostrado, é com seu Zaratustra (doravante, $\mathrm{Za}$ ) que Nietzsche faz claramente ver a importância dos signos para o seu filosofar. ${ }^{28} \mathrm{E}$ isso pode ser atestado já em suas "privadas" intenções com essa obra. Num conjunto de anotações preparatórias de seu livro capital, ele revela seu esforço para fazer seu Zaratustra

falar por meio de figuras, danças, tons e silêncios: e para que existiria o mundo todo, se o mundo todo não fosse signo e alegoria! (KSA $11,31[51])$.

Ora, é exatamente nesse contexto que, anos mais tarde, quando da composição de EH, surge uma decisiva, porém bastante complexa, aproximação: seu Zaratustra consagra-se, afirma Nietzsche em EH (Za 6), como "ato supremo" de seu "conceito de Dioniso", mas isso não quer dizer, no entanto, que ele representa sua definitiva realização, enquanto forma mais acabada de "superação" do tipo redentor, enquanto oposição ao signo "crucificado". ${ }^{29}$ Nietzsche aguardou ainda mais três longos anos, depois da composição final do quarto livro de Za (1885), para, então, plenamente, alcançar sua antissimbólica cristã, seu signo para um deus que, realizan-

\footnotetext{
${ }^{28}$ Sobre isso, cf.: STEGMAIER, Werner. "Signos de Nietzsche". In. STEGMAIER, W. As linhas fundamentais do pensamento de Nietzsche. São Paulo: Vozes, 2014.

${ }^{29}$ Sobre a imagem do dionisíaco em Za, consultar: RESCHKE, Renate. „Die andere Perspektive: Ein Gott, der zu tanzen verstünde. Eine Skizze zur Ästhetik des Dionisyschen im Zarathustra“. In GERHARDT, Volker (hg.) Also sprach Zarathustra. Klassiker Auslegen. Berlin: Akadamie Verlag, 2000.
} 
do as prédicas de Zaratustra, "entende de dançar" ${ }^{30}$, no qual ainda "se pode crer"; só em EH, Nietzsche cria sua semiótica para "uma expressiva força violenta de vitalidade e um sublime, sublimado espírito da cultura" (RESCHKE, Renate. op. cit. p. 263): Dioniso. Na "dança” de seus signos, de suas palavras, de suas imagens, em suma, no emprego musical (ditirâmbico) de sua linguagem, estaria também representada sua contraperspectiva à perspectiva do crucificado, segundo a qual signos devem se refugiar no inapreensível; em outras palavras, estaria representada ali uma contraperspectiva contra a perspectiva de um tipo para quem signos não mais oferecem determinada interpretação, uma que designe seu "querer-poder". Desse ponto de vista, os Ditirambos de Dioniso (doravante DD), última e não finda composição de Nietzsche, é o projeto decisivo para o máximo valor semiótico de uma linguagem anticristã.

Qual linguagem um tal espírito, a sós, falará consigo? A linguagem dos ditirambos. Eu sou o inventor dos ditirambos. Ouvir-se-ia como Zaratustra consigo fala ante o Nascer do Sol (III, 18): uma tal felicidade

\footnotetext{
${ }^{30}$ Zaratustra diz numa famosa passagem: „Ich würde nur an einen Gott glauben, der zu tanzen“. Cf. Za "Do Ler e do Escrever", p. 50. Reschke faz dessa temática o fio condutor de sua importante análise das "imagens” dionisíacas em Za. Ela afirma: „Sicher ist die Trinität Dionysos-ZarathustraNietzsche nicht ohne eine gewisse Spekulation. [...] Dionysos' Geheimnis offenbart sich im Tanz, es ist Tanz. Die Welt ist seine Bühne, und wo sein Zauber sie berührt, wandelt sich die ermüdete Kultur zum Leben [...] . Dionysos Grenzgängertum zum Ästhetischen hin realisiert sich wesentlich in traum(tänzerischer) Vision. Sein bukolisches Moment ist zugleich sein mimetischtheatralisches. Nietzsche verläßt sich auf die ästhetische Relevanz des Tanze(n)z und radikalisiert sie zur crux seiner Alternative gegen eine Kultur, die sich wesentlich kunst-, körper- und sinnenfeindlich zeigt. Auf der Suche nach dem Körper(lichen) findet er Dionysos, den tanzenden Gott; im Mimetischen des Tanzes, in der virtuosen Beherrschung rhythmisierter Körpesprache entdeckt er den Symbolwert fürs Heitere und Leitere, für den freien Geist. [...] Die Signifikanz der Gesten und die Lust an der Bewegung, das Zusammen- und Wechselspiel von Bewegung und Ruhe oder Tempo, Rhythmus und Takt, der dadurch körperlich emphatische Vollzug von Selbstdarstellung und Kommunikation in einem lassen für Nietzsche den Tanz zu einer äasthetischen Mitte um zum Maß der (für die) Kultur werden, in der und an dem sie zu werten ist und sich zu beweisen hat". RESCHKE, Renate. op. cit. pp. 265-6.
} 
esmeraldina (smaragdenes Glück), uma divina sutileza jamais teve língua antes de mim. E também a mais profunda melancolia de um tal Dioniso torna-se ainda ditirambo. Tomo, como signo, a Canção Noturna, o imortal lamento (unsterbliche Klage) de ser condenado, por superabundância de luz e poder, pelo seu Sol-Natureza, a não amar. (EH Za 7)

Ditirambo é a linguagem do deus não mais sob comando de um não-querer-ser-afetado. A linguagem de um tal deus não "abrevia" para tornar inapreensível ou indiferente o uso do signo; se a linguagem ditirâmbica quer a polissemia, bem como não se fixar "em conceitos", é porque quer, diferentemente à tradição, dar sentido, dar sua interpretação, uma que, por sua vez, opta por "cantar" e não mais "conceituar". Cantar ao invés de conceituar implica um uso dos signos que não mais tem necessidade (metafísica) de um conceito de conceito para o compreender, que não carece de um sentido que se estabiliza em um "sentido universal". Os signos de Dioniso são signos de sua interpretação, de sua vontade de dar sentido. Werner Stegmaier já havia chamado atenção para a ressignificação filosófica desse deus, Dioniso, em relação àquele concebido em sua primeira obra, O Nascimento da Tragédia: Dioniso, lembra Stegmaier, "é o conceito de um indivíduo, o conceito de um deus estranho e dificilmente compreensível, que viveu e morreu não apenas uma vez, mas inúmeras, que continuamente despertou novas forças nos homens, extasiando-os e enfurecendo-os de tal modo que eles o despedaçaram". ${ }^{31} \mathrm{Um}$ sentido que rejeita o fixar, mas que, ao mesmo tempo, não abre mão de determinar um valor, é algo estranho à tradição filosófica. Mas essa perspec-

\footnotetext{
${ }^{31}$ STEGMAIER, W. „Nietzsches Kritik der Vernunft seines Lebens” [...] , p. 177 ss.
} 
tiva de Nietzsche sobre o uso de signos sob a ótica da linguagem ditirâmbica (signos passíveis de "despedaçar") não faz frente apenas à necessidade metafísica de se estabelecer um sentido fundamental, por meio de um conceito de conceito, para as coisas. Ele propriamente se opõe - e é isso que nos interessa aqui - àquele uso característico dos signos pelo tipo Jesus, que não visa sequer ao conceituar, não visa a "fórmulas", mas simplesmente é indiferente, desinteressado na evocação e alusão simbólica.

O valor semiótico de $\mathrm{DD}$, obra última, porém não publicada, e seu estatuto no pensamento maduro de Nietzsche, foi amplamente discutido por W. Groddeck em seu comentário histórico-filológico. ${ }^{32}$ Nietzsche já havia dito em EH que seu Zaratustra significa um nome "para autossuperação da moral da veracidade, a autossuperação dos moralistas em seu oposto - em mim - [...]" ${ }^{33}$; mas é com a linguagem dos ditirambos que Nietzsche atinge, assim nos parece, a máxima energia semiótica de sua linguagem. Ditirambos é, num certo sentido, metalinguagem: é a linguagem sobre o processo de criação e realização dos signos linguísticos enquanto signos; ela se concretiza como a própria invenção (Erfindung) de signos para toda espécie de significar. Há sim, sob esse aspecto, um traço genético entre a

\footnotetext{
${ }^{32}$ Certamente, o estudo mais consistente nessa área de pesquisa continue sendo o de W. Groddeck. GRODDECK, W. Die 'Dionysos-Dithyramben'. Bedeutung und Entstehung von Nietzsches letztem Werk. 2 Bde. Monographien und Texte zur Nietzsche-Forschung Band 23. Berlin / New York: Walter de Gruyter, 1991. Aliás, no penúltimo parágrafo do segundo volume, o autor destaca: „Für das Verständnis der 'Dionysos-Dithyramben' ist das Werk 'letzter Hand' - und ein solches hat Nietzsche am 2. Januar 1889 bestimmt - eine unabdingbare Voraussetzung, denn der Zyklus der 'Dionysos-Dithyramben', Nietzsches letztes Werk, ist eine Dichtung über das Werk Nietzsches, in dessen Zentrum die dreiteilige Dichtung 'Also sprach Zarathustra' steht." p. 478.

${ }^{33}$ EH "Por Que Eu Sou Um Destino" 3.
} 
linguagem que Nietzsche apresentou em, e por meio de, seu Zaratustra e aquela de DD, elaborada no final de sua vida intelectualmente produtiva.

Ditirambo é o nome arcaico para Dioniso, o "deus que é, do ponto de vista formal e de conteúdo, idêntico ao ditirambo, o concurso de canção em seu louvor" ${ }^{34}$; e mesmo que o próprio Nietzsche - e ele sabia disso ${ }^{35}$ - não seja, ao pé da letra, o primeiro inventor dos ditirambos, isso, no entanto, não seria objeção suficiente contra a originalidade da invenção, pelo ditirambo nietzscheano, de Dioniso enquanto deus-signo. Segundo Groddeck, essa perspectiva é, aliás, amplamente apresentada no quinto ditirambo ("O Signo Luminoso” [Das Feuerzeichen]), no qual o “"signo’ é a condição de uma renovada autocriação da linguagem ditirâmbica depois de sua dissolução no quarto [ditirambo]". Dioniso é deus-signo, "por definição" antitético, contraditório, polissêmico ${ }^{36}$ Enquanto contra-signo ao signo do crucificado, porta em si uma vontade de significação, uma afirmação de um próprio, interessado (e não mais indiferente) uso de palavras, imagens, sons, um querer de-signar, que de imediato apresenta um acúmulo de energia semiótica, a qual, quando dissipada, torna a ser recriada sempre e de modo "outro". A condição para a contínua criação desse (paradoxal) deus-

\footnotetext{
${ }^{34}$ BAEUMER, Max L. „Dialetik und zeitgeschichte Funktion des literarischen Topos“. In Toposforschung. Hg. v. Max L. Baemuer. Darmstadt 1973, pág 310. Apud. GRODDECK, W. Die 'Dionysos-Dithyramben' [...] , Segundo Volume: Introdução, p. XVIII

${ }^{35}$ Groddeck (ibid.) aponta para esse fato, citando um texto do assim chamado "período militar", no qual Nietzsche afirma: „Der Erfinder des Dithyrambos ist Arion.“ In. NIETZSCHE, F. Historisch-Kritike Gesamtausgabe Werke. Hrsg. H. J. Mette et alli. München: DTV, 1933. Aqui, Volume 5, pág. 378.

${ }^{36}$ Em JGB 295, escreve Nietzsche: „ [...] Dionysos, jener grosse Zweideutige und Versucher Gott [...]

“KSA 5, p. 238.
} 
signo é justamente seu ser-semioticamente-despedaçável.

À mencionada "felicidade esmeraldina (smaragdene Glück)" de Dioniso, produzida pela linguagem ditirâmbica, oriunda de profundos sentimentos melancólicos, de um "lamento imortal (unsterbliche Klage) por estar condenado a não amar" - a uma tal felicidade Nietzsche tornou mais do que uma simples imagem que visava a ilustrar os opostos sentidos carregados por seu deus-signo; a ela foi destinado o sétimo ditirambo de DD, nomeado pelo autor de Klage der Ariadne (O Lamento de Ariadne). ${ }^{37} \mathrm{O}$ Leitmotiv desse ditirambo é o "tornar-visível" de Dioniso a partir de um raio (tema que também aparece em Za, quando da anunciação, no prólogo, de seu Übermensch). Após rompantes de histeria de Ariadne, de profunda melancolia, na estrofe final, precedida de advertência que indica a entrada do deus ex machina, ocorre o clímax do ditirambo (no sétimo canto) com a aparição do deus-signo.

Um raio. Dioniso tornar-se visível em beleza esmeraldina (smaragdene Schönheit).

Dioniso:

Sê serena, Ariadne! [...]

Tens curtos ouvidos, tens meus ouvidos:

Meta aí uma serena palavra! -

Não se tem primeiro que se odiar, quando se deve amar? [...]

Eu sou teu labirinto [...] (KSA 6, pág. 401)

Não se poderia supor haver aqui qualquer tipo de simbolismo, Dioniso não representa, na linguagem de Nietzs-

\footnotetext{
${ }^{37}$ Não tão profunda quanto a leitura de Groddeck, para uma análise desse sétimo ditirambo, consultar: THEISEN, B., „Die Gewalt des Notwendigen. Überlegungen zu Nietzsches DionysosDithyrambus 'Klage der Ariadne'“, In Nietzsche-Studien 20, 1991.
} 
che, um pessimismo à la fin du siècle. Cada elemento é dotado de polissemia, mas não há aqui qualquer indiferença no uso dos significantes. Para encaminhar uma conclusão, caberia explicar o porquê.

Apenas no ditirambo VII, Dioniso "entra em cena", e a intervenção de Nietzsche que prepara sua entrada, indica, aliás, um redobro, um quase recurso teatral (no que tange ao aviso) de seu advento. Nietzsche já havia feito de Ariadne, no capítulo "Zaratustra" de EH (seção 8), uma "resposta" para o ditirambo que cantasse as dores de Dioniso. No entanto, aquela para quem Nietzsche destina o "lamento" nesse sétimo ditirambo, segundo Groddeck, remetendo à complexidade semiótica de DD, nada tem a ver com a Ariadne de outras passagens de seus textos de juventude. Ao retomá-la, em seu pensamento maduro, primeiro e de modo despretensioso em Para Além de Bem e Mal 295, e em seguida, em EH, a figura de Ariadne ganha "um especial significado, não porque 'Ariadne', nas obras autorizadas de Nietzsche, é aqui chamada pela primeira vez, mas, sobretudo, porque o nome de Dioniso vai novamente aparecer, desde a publicação de O Nascimento da Tragédia, nas obras de Nietzsche". ${ }^{38}$ Ariadne passa a corresponder à semiótica do deus-signo Dioniso; por isso, seu significado é muito maior do que aquilo que Nietzsche vai colocar em sua boca. Dioniso é seu ditirambo, é também seu ouvido. E como seu "curto ouvido" ele se faz ouvir, por Ariadne, quando lhe dá esta "serena palavra": labirinto.

Labirinto é aqui muito mais do que metáfora anatômi-

${ }^{38}$ GRODDECK, W. Die 'Dionysos-Dithyramben' [...] , Segundo Volume, pág. 176-7. 
ca (labirinto como porção óssea, também membranosa, do ouvido interno): labirinto é Leitmotiv de todo o texto ${ }^{39}$; essa simbólica está presente em todo lamuriar de Ariadne, em seu descontentamento histérico e angustiado, dores do nãoamor, até sua consumação, na cena poética final do ditirambo, com a junção do deus à imagética: Eu [Dioniso] sou teu labirinto. Não há diálogo; Dioniso parece falar consigo mesmo quando, tornando-se visível a Ariadne, define-se a si como labirinto-ouvido e faz dessa linguagem-labiríntica o motivo do seu ditirambo. Não é o lamento de Ariadne que encerra a música do ditirambo; mas com aquele outro desfecho, Nietzsche parece querer fazer o leitor ouvir o labirinto-Dioniso: quer fazer ouvir a felicidade e beleza esmeraldina de um lamento que, a contrapelo da angústia e dor de Ariadne, é imortal. O verso final funde, dessa maneira, "forma" do deus, que, de um raio, "é tornado visível", com seu conteúdo: o signo-labirinto. Sob esse aspecto, a máxima energia semiótica é alcançada com a arrebatadora significação final do signo (Dioniso) em signo (labirinto): eu sou[...]labirinto.

Tudo isso significa a palavra Dioniso: eu não conheço simbólica mais suprema do que esta simbólica grega, a de Dioniso. (Crepúsculo dos Ídolos, "O Que Eu Devo Aos Antigos" 5, KSA 6, pág. 159)

Dioniso, que no mito é despedaçado e por isso é infinitamente individualizado e pluralizado, aquele que "renasce continuamente, retornando da destruição", é para Nietzsche, como ele próprio escreve privadamente, o deus do sentido trágico (por isso, essencialmente, anticristão) para a vida (segundo anotação de 1888, 14[89]), sintetizando em si

\footnotetext{
${ }^{39}$ GRODDECK, W. Die ‘Dionysos-Dithyramben' [...] , Segundo Volume, pág. 208 ss.
} 
"o símbolo mais misterioso da suprema afirmação do mundo e transfiguração da existência jamais vista na terra" (anotação de 1885, 41[7]). Assim, como símbolo transfigurador, um que para o pensar e o viver encontra-se em contínua transfiguração de "forma" e "conteúdo" (a figura da destruição como condição para o renascimento), Dioniso pode ser entendido como um signo, ou melhor, como uma semiótica que se antagoniza àquela do tipo Jesus enquanto (signo do) "crucificado". Aliás, uma rigorosa análise dessa semiótica ditirâmbica é tão mais difícil quanto mais complexos e polissêmicos são os signos que Nietzsche cria, encena ou faz, propositadamente, despedaçar-se em suas obras de maturidade. Dioniso é mais do que imagem poética; é, isto sim, uma forma exemplar do que Nietzsche entendia, especialmente em sua obra de maturidade, por filosofar. Ao se colocar, no Crepúsculo dos Ídolos ("O Que Eu Devo aos Antigos" 5), como o último discípulo do deus-signo, Nietzsche fez notar seu já desejado plano de criar "uma forma divina de filosofar" (KSA 11, 34 [182], p. 483), um genuíno esforço para criar semioticamente "o instinto da vida”, "o futuro da vida", a "eternidade da vida" (ibid.). Isso ele anota para si, privadamente, em um apontamento do início - verão de 1888:

Nós, muitos ou poucos, que ousamos novamente viver em um mundo cuja moral foi desmoralizada (entmoralisierten Welt), nós, pagãos pela fé: nós somos provavelmente também os primeiros que compreenderam isto, a saber, o que é uma fé pagã: ter que se representar seres mais superiores do que o homem, porém, tais seres para além de bem e mal: ter que estimar todo ser-superior (Höher-sein) como serimoral (Unmoralisch-sein). Nós acreditamos no Olimpo - e não no “crucificado" [...] (KSA 13, 16[16], p. 487) 
Para então fazer desse contexto, em EH, o destino de seu filosofar, cuja última linha expressa justamente a famosa e enigmática questão:

Entenderam-me? - Dioniso contra o crucificado [...] (EH "Por Que Sou Um Destino" 8)

A filosofia madura de Nietzsche ainda fornece inexplorados campos de pesquisa para aqueles que se atrevem a não se deter simplesmente em chavões e filosofemas extenuantes. Talvez exatamente por isso valesse à pena não mais menosprezar a não despropositada advertência colocada pelo próprio filósofo aos seus leitores (e dentre eles, com maior ressalva ainda, aos seus intérpretes) logo no início do prefácio a O Anticristo. Lá ele afirma de modo estridente para certos ouvidos: "Este livro pertence a pouquíssimos".

Abstract: This article aims to analyze, at first, the meaning of Jesus-figure by Nietzsche's psychology presented in The Antichrist. More precisely, this article starts from a questioning of this typology; then, it aims to converge this psychological strategy with a semiotics, i.e., an analysis of uses of signs by the "type" Jesus. After contextualizing the discussion on the Jesus-figure as "symbolist" and "antirealist", this article goals to show how Nietzsche elaborates in his later works (1888 writings) an symbolic confrontation between Jesus and Dionysus, and from that we seek to indicate some conclusions.

Keywords: Nietzsche; sign; Jesus; Dionysus.

\section{REFERÊNCIAS}

BALAKIAN, Anna. O Simbolismo. Trad. José Bonifácio A. Caldas. São Paulo: Editora Perspectiva, 1985.

BAUDELAIRE, C. Les fleures du mal. Préface et commentaire Robert Sctrick. Paris. Édition Pocket: 1998.

BOURGET, Paul. Essais de Psychologie Contemporaine. 
Édition établie et préface par André Guyaux. Paris: Gallimard, 1993.

CAMPIONI, Giuliano. Les Lectures Françaises de Nietzsche. Trad. Christel Lavigne-Mouilleron. Paris: PUF, 2001.

GRODDECK, W. Die 'Dionysos-Dithyramben'. Bedeutung und Entstehung von Nietzsches letztem Werk. 2 Bde. Monographien und Texte zur Nietzsche-Forschung Band 23. Berlin / New York: Walter de Gruyter, 1991.

MÜLLER-LAUTER, W. His Philosophy of Contradictions and the Contradictions of his Philosophy. Translated by David J. Parent. Urbana and Chicago: University of Illinois Press, 1999.

NIETZSCHE, F. Sämtliche Werke: Kritische Studienausgabe in 15 Bänden. Hg. G. Colli und M. Montinari. Berlin/New York: Walter de Gruyter/DTV, 1999.

. Historisch-Kritike Gesamtausgabe Werke. Hrsg. H. J. Mette et alli. München: DTV, 1933.

. Sämtliche Briefe. Kritische Studienausgabe. hg. G. Colli u. M. Montinari. Berlin/New York: DTV \& Walter de Gruyter, 1986.

PESTALOZZI, K. „Nietzsches Baudelaire-Rezeption“" In: Nietzsche-Studien 7, 1978.

RENAN, E. Vie de Jésus. Michel Lévy Frères Libaires Editeurs: $2^{\text {a }}$ Ed. Paris, 1864.

RESCHKE, Renate. „Die andere Perspektive: Ein Gott, der zu tanzen verstünde. Eine Skizze zur Ästhetik des 
Dionisyschen im Zarathustra“. In GERHARDT, Volker (hg.) Also sprach Zarathustra. Klassiker Auslegen. Berlin: Akadamie Verlag, 2000.

SOMMER, A. U. Friedrich Nietzsches 'Der Antichrist': Ein philosophisch-historischer Kommentar. Basel: Schwabe \& CO. AG Verlag, 2000.

STEGMAIER, W. "A crítica de Nietzsche da razão de sua vida - Para uma intepretação de O Anticristo e Ecce homo". In. STEGMAIER, W. As linhas fundamentais do pensamento de Nietzsche. São Paulo: Vozes, 2014.

THEISEN, B., „Die Gewalt des Notwendigen. Überlegungen zu Nietzsches Dionysos-Dithyrambus 'Klage der Ariadne'“. In: Nietzsche-Studien 20, 1991.

VIESENTEINER, Jorge L. "Estrutura formal e semântica do argumento autogenealógico". In. Cadernos de Filosofia Alemã, v. 20, p. 105-119, 2015. 